\title{
The Risks of Cloud Computing in Accounting Field and the Solution Offers: The Case of Turkey
}

\author{
Serkan ÖZDEMIR \\ Pamukkale University, \\ Buldan Vocational School, \\ 20400 Buldan Denizli-Turkey \\ sozdemir15041976@gmail.com
}

\author{
Cemal ELITAŞ \\ Yalova University, Faculty of Economics \\ and Administrative Sciences, \\ 77100 Yalova-Turkey \\ cemalelitas@gmail.com
}

\begin{abstract}
Cloud is the system that maintains common information sharing among the information devices. It is known that there are always risks and that hundred per cent safety is not available in the environments of information technology. Service providers that operate in accounting sector and utilize the cloud technology are responsible for keeping and preserving the digital financial data that are vitally important for the companies. Service providers need to take all the necessary technical measures, so that the digital data are not damaged, lost and possessed by the malicious third parties. The establishments that provide service for accounting systems by utilizing the cloud computing opportunities in accounting field need to consider the general and countryspecific risks of cloud computing technology. Therefore, they need to build the necessary technical infrastructure and models in order to run the system flawlessly and to preserve the digital data of the establishments in a secure environment.
\end{abstract}

Keywords: Cloud, Cloud Computing, Accounting, Cloud Technology, Data Security

\section{Introduction}

As the Internet has commercialized and become more popular, it is now widely used in the communication and information sharing of companies. Today, the fact that a vast quantity of information can easily flow through the network reduced the data and software hosting burden of personal devices. The users can easily access to the web resources via new tools and services thanks to the power of broadband connection (Selvi, 2011). But this situation has increased the amount of digital information that has to be kept and it is almost impossible for the personal computers to save this data. Information sector set off on new quests for the solution of the problem $(\mathrm{Hu}$ and $\mathrm{Hu}$, 2010).

The most important development that has become prominent in recent years in information technologies in accordance with the above-mentioned requirements is cloud computing (Koyuncu, 2011). Actually, many people run some services unwittingly through the cloud computing infrastructure today. The products of the companies such 
as Facebook, Google App, iTunes and Yahoo can be shown as the examples of cloud products.

Cloud computing, which is one of the most important concepts that is named as the second boomer of web technology and which is expected to lead the business world in the future, is the servicing of information technologies as the external source in short. Cloud computing creates a suitable environment for the establishments under the current economic conditions of competition. Today, business world requires speed and agility more than ever before. Besides, establishments need the information systems in order to continuously control both their business processes and costs. The popularity of cloud computing, which provides the establishments with the opportunity to build an information structure that can fulfill all these needs at the same time, in business world increases day by day for these reasons.

All the individual users, small or medium-scale establishments, and large companies or establishments can utilize the cloud services. Cloud services can be accessed via any device that can connect to Internet.

Cloud computing, which is used to reduce the traditional information costs in the establishments, has become a shining star for the last five years. The researches conducted by International Data Center (IDC) have revealed the worldwide growth. In information and communication technologies, the portion of cloud computing costs grew quickly year by year and reached to 44.2 billion dollars in 2013. The most important reason why the information technology providers focus on the cloud model is that the sector grows very quickly. In this growth, traditional information technologies are five times more than the distribution models (Yapıc1, 2010). The expectation towards that most of the business applications will be carried out through the cloud services in the future is the indicator that the sector will grow more. The sector that adopts and puts into practice the cloud computing services in a short time is the service sector which also includes the accounting sector.

Cloud computing has been widely used in the accounting sector in recent years. The establishments that run and market especially web-based accounting software have the opportunity to provide their customers with higher-quality and cheaper service by utilizing the infrastructure and software services of cloud computing. Although there are many web-based accounting software in the market, few of them benefit from the cloud computing opportunities. But in ten years, it is foreseen that many applications of the web-based accounting software will have a cloud computing-based structure.

In today's competitive environment, it is the primary goal of the establishments to build and manage the accounting systems for a low cost and with advanced technological facilities within a secure structure that can be constantly and remotely followed. Accounting systems that benefit from the web-based cloud computing opportunities have the structure to fulfill these requirements. But the general risks contained within the cloud computing technology and the fact that it is a very new concept in accounting sector, and that its legal infrastructure has not been thoroughly built yet in Turkey and its security concerns raise a question mark in the minds of the establishments in terms of the operation of the system. Therefore, many establishments remain aloof from the accounting systems that utilize the web-based cloud computing.

The purpose of this study is to raise awareness in the establishments that operate in Turkey by giving information about the properties, types, application areas, 
advantages and risks of cloud computing and to propose a solution aimed at minimizing the possible risks to be created by its use in the accounting field.

\section{Definition and Scope of Cloud Computing}

The fact that Internet has arisen and become widespread has made significant developments in data exchange. The data stored in specific centers have been offered to a large user group through the web and the data trapped in the data centers have opened up to the outside world via Internet. Use of Internet has quickly been popular in office and personal computers and then in mobile devices. In accordance with the fast consumption by the user, the web standards have begun to be reshaped and new web technologies and services have appeared. Between Web 1.0 and Web 2.0, technologies such as SOAP and Point-to-Point (P2P) were put into use, and today, between Web 2.0 and 3.0, rich Internet applications have come up and business applications have begun to be prepared (Atay, 2010).

Within the process, user requests have improved in the direction of using the applications independently from time, space and platform. In order to meet these requests, a new development called as "cloud computing" has come up (Selvi, 2011).

It is possible to consider cloud computing as the scalable hardware infrastructure that is shared for answering the requests on time. It is also a distribution model that serves the purpose of accessing to the information resources and applications on a data center through the web at any time and place upon request. Although cloud computing is an important technological development, it is not an unusual model that requires a big change. The data delivery process, which every establishment has done through the limited-scale application and data centers within their body so far, has begun to be offered by cloud computing through the large-scale data centers of private institutions (Selvi, 2011).

All the basic information about cloud computing (Types, Modes, Stakeholders, Substructure, Benefits and Features) to be detailed later is summarized in Figure 1 (Kuyucu, 2011).

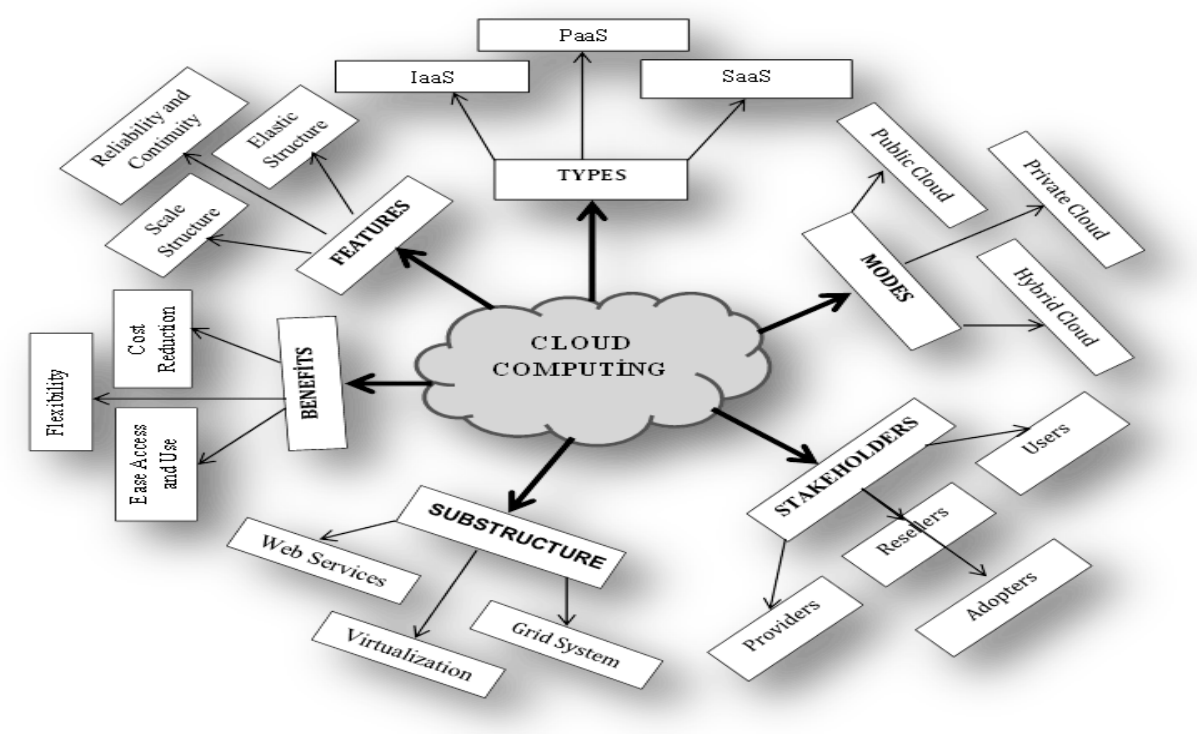

Figure 1. Key Features of Cloud Computing 


\subsection{Substructure}

Cloud computing is a developing technology and the implementation of this information model has been possible with three different technologies that have developed recently. These three technologies that enable cloud computing and build its infrastructure are web services, virtualization and grid computing (Seyrek, 2011).

Web services are platform-independent autonomous software that can be accessed through Internet. As these services are written according to the open standards, they are independent from the programming language and operating system. Thus, the web services developed by different people can be used by the software developers, who use the other platforms and technologies, and new software can be quickly developed. As these services can be used by other software via the standard interfaces and protocols (SOAP, XML, etc.) through Internet, low-cost and distributed new applications can be quickly developed. With the web services, software developers develop new applications by quickly integrating their own software into the other services on the Internet, and this achieves economic benefit (Seyrek, 2011).

The other important development that constitutes the infrastructure of cloud computing is the virtualization technology. Lots of virtual computers can be formed on a few physical computers and the existing hardware capacity can be used much more efficiently thanks to the virtualization technology. There are many host computers and storages that launch the web servers, database servers and the other business software in today's establishments. With virtualization, lots of virtual servers that run different operating systems and applications on a physical server are created. So, the establishments reduce their capital investments by using less equipment, and also reduce the operational costs related to power consumption and maintenance caused by these servers. In addition, various maintenance and management processes such as the update, upgrade and back-up of these systems are more easily carried out by the information technologies department, and this provides advantage to the establishments in terms of the uninterrupted service of these systems which are very important for the operations of the establishment (Seyrek, 2011).

The third technology regarding the cloud computing is grid computing technology. Grid computing means that the resources such as calculation, storage and memory of computers in different places are gathered and shared through high-speed computer networks. So, computers with larger capacity can be built by using the idle capacity of the computers in different places (Maqueira-Marin et al., 2009). Grid computing not only means the combination of the calculation power of many computers. It also means that a program is run in a parallel and distributed way by allocating it to lots of computers (Sultan, 2010).

As it can be seen in Figure 2, the development process of cloud computing starts with the formation of the network topology between the intra-computers. And then, this continues with Internet sharing in the computers on the network. But this sharing is in local scale. The development process goes on with the formation of a worldwide web network. The computers connected to each other through the web build the grid system by joining their resources. In the last stage of the process, the cloud system, where the services and applications are shared, is formed (Bojanova and Samba, 2011). 


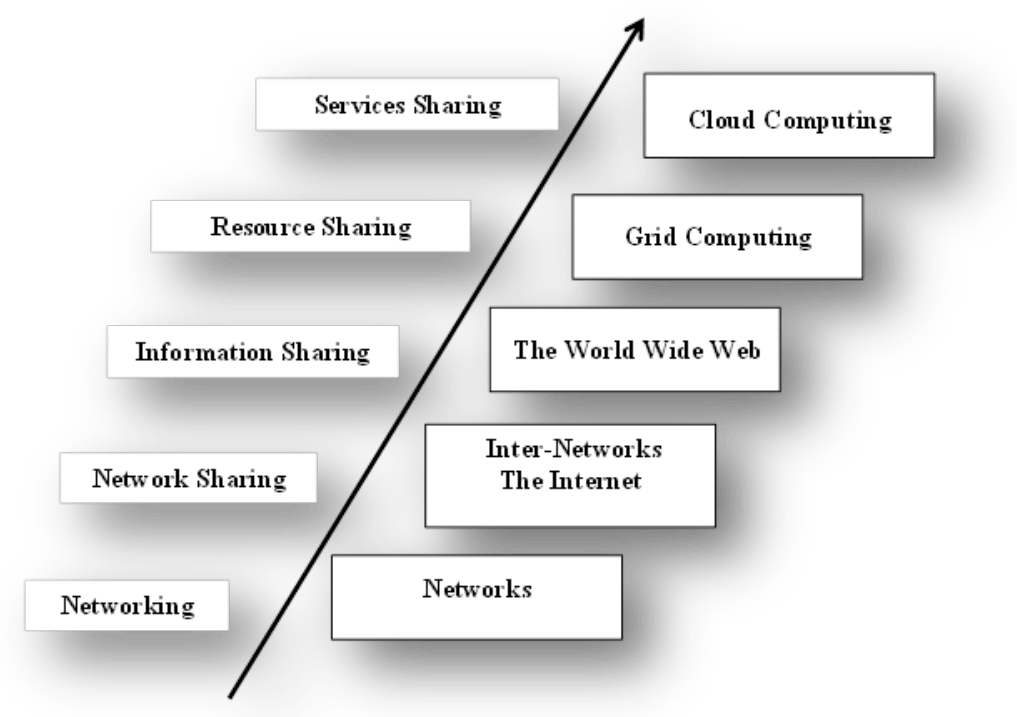

Figure 2. The Evolution of Sharing on the Cloud

\subsection{Service Types}

It represents the layer where the cloud applications are displayed. The applications that run on a cloud infrastructure are offered to the service users as a service on this layer. The applications can be accessed through any device with Internet connection via the tools such as web browser without any limitation on time and space. There are three types of cloud computing model.

a) Software as a Service (SaaS): It is the model offered as service along with its required updated web-based versions that address the corporate or end user and that may contain the financial and office applications and even the software of e-mail service given to the individual users. Here, the software that the establishments need are kept in the servers of the institution providing this service, and the work is done by running the software through these servers without installing it on their own computers. As the software is also used by many customers, it is a service that can be received for a very small fee without any license fee and upcoming update problems. The accounting software that provide service utilizing the web-based cloud computing can be given as an example to this structure.

b) Platform as a Service (PaaS): In such a cloud model, the environment created to develop new applications is offered as a service. You can build a new application of your own that runs in the infrastructure of the establishment providing cloud service, and you can provide service to the users through the servers of the establishment. These services can be development tools, configuration management and deployment platforms. The service provider designs and builds the application development, the environment where the application will run, the supplementary services and the infrastructures. The user develops the application according to this platform. The service structure of the establishments that provide accounting software service utilizing the web-based cloud computing can be given as an example.

c) Infrastructure as a Service (IaaS): In this model, the service provider provides the user with the processor speed, memory, storage and network services that the user 
can utilize in full capacity and can install the operating system and other software on. Like the other models, the user is unaware of where these computers are, how they are configured or how they are maintained. They only request this service within the specified quality standards (Armutlu and Akçay, 2013).

The interaction structure of the cloud computing service types is described in Figure 3. Infrastructure as a Service (Iaas) is offered to the application managers that provide platform service and to the end users by the cloud computing service provider. Platform as a Service (Paas) is offered to the end users as Software as a Service (SaaS) through the support of cloud computing infrastructure services with the applications built by the establishments. In the software service, the end users can get platform service from the application managers. In addition, they can get data storage and network services from the infrastructure services.

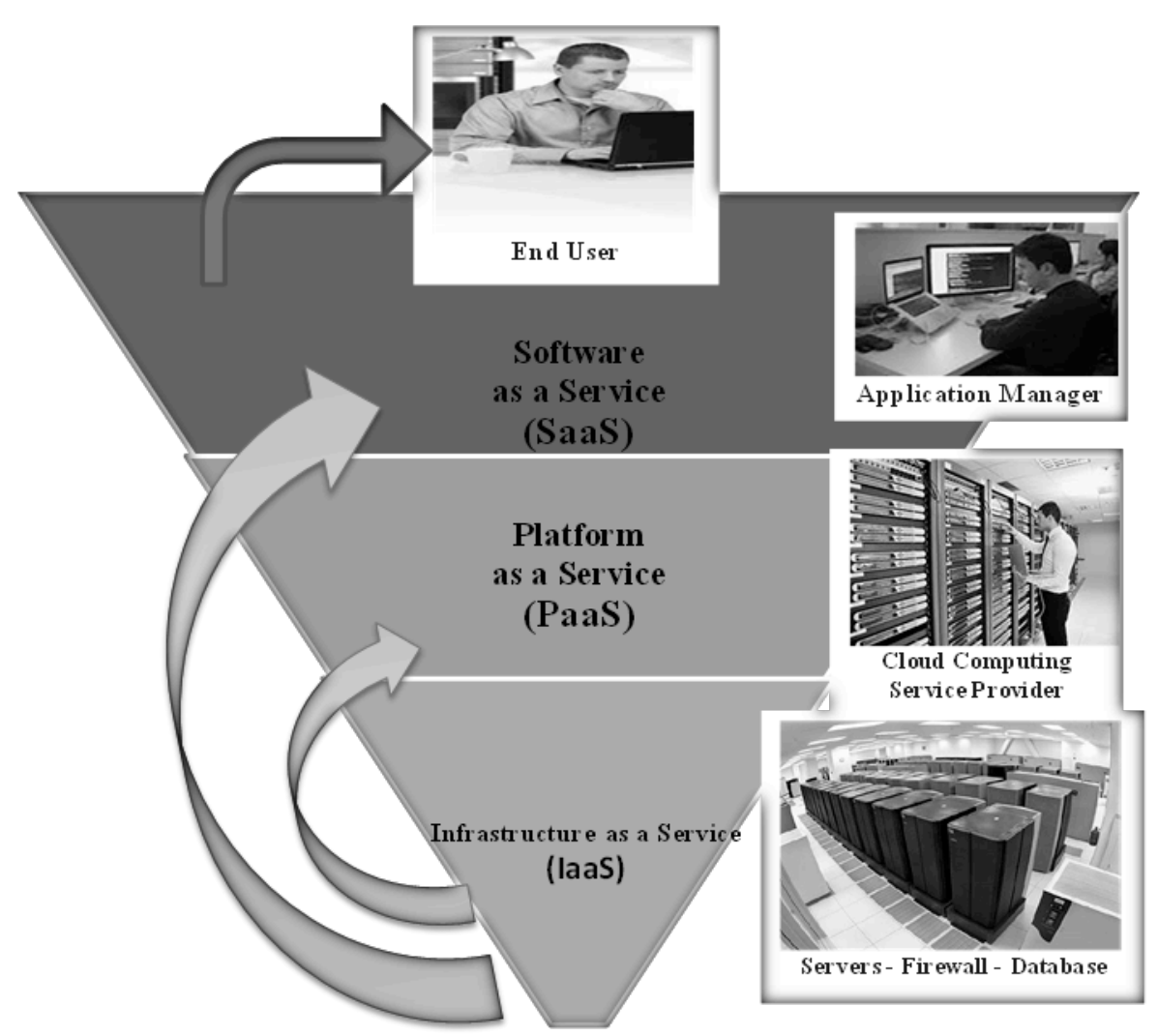

Figure 3.Types of Cloud Computing Services

\subsection{Models}

Cloud computing service models have three genres in terms of the utilization type. Public Cloud, Private Cloud and Hybrid Cloud. These basic service models can be offered both separately and with the combination of three or two of them in order to create the service structure.

a) Public Cloud: These are the public domain services over Internet as well as belonging to a third party that provides cloud computing service. Here, the user groups 
access to the services through the web applications. For example, Amazon, Google, GoGrid, etc. (Y1ld1z, 2011).

b) Private Cloud: This is the cloud model that an establishment builds on the data centers within its own body. It is a traditional model that has been applied in the information world for a long time. The works such as the building of the infrastructure, supplying the software, management and maintenance processes of the system, maintaining the continuance of data security and service are completely a burden on the establishments. From this aspect, it is criticized as it contradicts with some advantages provided by cloud computing (Selvi, 2011).

It is a model which is preferred in situations when there is a need for the highlevel data security and privacy. Private cloud provides service to the limited number of users of the establishment behind a firewall (Selvi, 2011). Web-based accounting applications that utilize cloud computing have such a structure.

c) Hybrid Cloud: It is the combined use of the above-mentioned types. For example, an establishment can use outsourcing in addition to the private services of its own. Data storage service can be given as an example of this (Y1ld1z, 2011). Today, most of the web-based accounting applications have obtained a hybrid structure by integrating the cloud computing facilities to their applications more.

\subsection{Features}

a) Scalability: The use of information infrastructures and the amount of load may vary according to the time in the establishments. However, it is not rational to make large infrastructure investments for the density that occurs at definite times. It is a profitable solution in terms of cost and labor to use the resources when they are needed and to release them when the requirements are met. Cloud computing is a scalable structure that provides the users with useful solutions in this respect.

b) Elastic Structure: Cloud computing is a flexible structure that enables the effective use of the resources without the necessity of the service recipients to intervene in the infrastructure problems. The performance audit of the system, enabling new resources in case of need, releasing the unused resources when the needs are fulfilled and management of the resources in line with the demands are carried out by the service providers.

c) Reliability and Continuity: In cloud computing, thanks to the back-up systems, the possibility of data loss or breakdown in the system operation is minimized and the continuity of business is maintained. Additionally, as long as there is no Internet connection problem, the cloud computing data centers that work coordinately in different geographical locations provide their users with uninterrupted service. The continuity of the system is maintained by immediately intervening in the breakdowns via the follow-up processes which are regularly performed on the consistently reinforced infrastructures.

\section{The Advantages and Risks of Cloud Computing in Accounting Field}

\subsection{Benefits}

Today, the traditional accounting software shown at schools have begun to be replaced by the web-based accounting software based on cloud computing. In recent years, the main objective and endeavor of lots of big establishments have been to build 
an Internet-based system where they can manage their financial data in any environment. Cloud computing provides the infrastructure that can fulfill all these requirements.

The potential advantages of cloud computing in accounting field from the point of view of the service providers and service recipients can be described as follows:

a) Cost Reduction: The establishments that use cloud computing do not have to make large amounts of investment on hardware as they use their applications through cloud service provider via Internet and as they store their data in the data centers of the service provider. These applications can also be used at any place with Internet connection without the limitation on time and space (Hu and $\mathrm{Hu}, 2010)$.

No matter what their size is, cloud computing-based accounting applications are a low-cost solution compared to the traditional applications. Cloud computing eliminates the need for purchasing an accounting software and does not require any extra payment and time loss for the updates unlike the traditional accounting software. Upgrade, maintenance, system management costs and the problems such as server failures are not the issues that the user needs to follow up anymore, and have become the subjects that are managed by the cloud accounting service provider.

b) Easy Access and Use: Cloud accounting applications enable the access to the financial data of your company at any time and place without the necessity to download and install a program in your computer. All you need is a computer and Internet connection. Cloud accounting applications can also be accessed from smart phones which are widely used today.

Besides, cloud computing provides advantage by eliminating the complexity of the management in data processing units. The operations of data processing units generally have a complex structure for the senior managers of the establishment. Because this is the matter that they do not understand very well, but that they are aware of the returns of the system, and that they allocate significant budgets with the expectations of improving, competing and making more profit. Cloud computing will eliminate most of the technical issues in the information operations to be conducted within the institution except the basic management problems that the managers can understand. This situation will create an uncomplicated and manageable information environment for the senior management of the institution. Here, if it is understood how much effective the support of the senior management is in the failure of the projects related to the information technologies, the advantage of cloud computing will be comprehended better (Y1ldız, 2011).

c) Advanced Technical Specifications: Cloud accounting applications can offer their users lots of improved features unlike the traditional accounting software. For example, it is not an easy job to manage the financial data of multiple interrelated companies at the same time. The system can be designed in accordance with the necessary mergers and privatizations of the companies. Service providers also offer the chance of automatic recognition of bank activities via the agreements that the companies make with the banks which they make a transaction at most. This situation can be considered as a milestone for transition to the automatic accounting records.

d) Flexible Total Ownership Costs: Today, all the business processes including the information systems are required to be structured so as to immediately change 
according to the growth and reduction status that may occur in business. Therefore, the system must be structured so as to provide flexibility. Due to the fact that it is serviceable when requested, that the installation cost is very low and that it can immediately respond to the rise or reduction in business, cloud computing will bring a more flexible structure to the establishments thanks to these features (Y1ld1z, 2011).

Service providers generally charge the cloud accounting applications as a bulk service pack. There is no payment except this fee. In addition, the subscription fee of the service providers in cloud accounting applications is generally non-fixed and may vary according to the company requirements and size.

e) Increased Business Performance: Cloud accounting applications help the accountants create real-time financial reports and clipboards by adapting to the changing business conditions in a short time. This situation creates an environment for the administrators to make instant and correct financial decisions and contributes to the performance increase.

f) Unlimited Backup: The establishments that use cloud accounting applications have the opportunity to back up their financial data at any time and any number. Backup data is kept in the servers of the service-providing establishment. So, the possible data loss is avoided.

g) Unrestricted Use of Installation, Support and Training Services: Service providers can remotely provide support to the establishments during the installation of web-based accounting software. Also, the problems occurred during use can be solved in a short time via the support lines.

h) Legal Updates are synchronously done without Paying Any Fee: Service provider allows all the users utilize this service simultaneously for free of charge by synchronously transferring the legal regulations to the system.

The use of cloud computing, which has become popular in information technology, has become widespread in accounting sector as well. Especially the establishments that provide packaged accounting software service have begun to utilize the cloud computing facilities more and more. Today, the traditional accounting software have begun to be replaced by the web-based accounting software based on cloud computing. In recent years, the main objective and endeavor of lots of big establishments have been to build a web-based system where they can manage their financial data in any environment. Cloud computing provides the establishments with an infrastructure that can fulfill all these requirements.

The traditional accounting software and cloud computing-based accounting software are compared in Table 1 and the differences are put forward. 
Table 1. Comparison Between Traditional and Cloud Computing-Based Accounting Software

\begin{tabular}{|c|c|}
\hline $\begin{array}{l}\text { Traditional } \\
\text { Accounting Software }\end{array}$ & $\begin{array}{l}\text { Cloud Computing-Based } \\
\text { Accounting Software }\end{array}$ \\
\hline Data are Entered Manually & Data are Entered Automatically \\
\hline Remote Access to System is not Available & Remote Access to System is Available \\
\hline Installation and Update are Done Manually & $\begin{array}{l}\text { Installation and Update are Done via Remote } \\
\text { Access }\end{array}$ \\
\hline $\begin{array}{l}\text { Independent Working Outside Workplace is } \\
\text { not Available }\end{array}$ & $\begin{array}{l}\text { Independent Working Outside Workplace is } \\
\text { Available }\end{array}$ \\
\hline Back-up is Done at Local Destination & $\begin{array}{l}\text { Back-up can be Done at Cloud Computing } \\
\text { System and Local Destination }\end{array}$ \\
\hline $\begin{array}{l}\text { Legislative Amendments are Followed } \\
\text { Individually }\end{array}$ & $\begin{array}{l}\text { Legislative Amendments are Followed Through } \\
\text { Cloud Computing System }\end{array}$ \\
\hline Declarations are Filled in and Sent Manually & Declarations are Filled in and Sent Automatically \\
\hline Time Loss in Transactions & No Time Loss in Transactions \\
\hline $\begin{array}{l}\text { Invoices and Other Official Documents are } \\
\text { Filled in and Sent Manually }\end{array}$ & $\begin{array}{l}\text { Invoices and Other Official Documents are Filled } \\
\text { in and Sent Through Web }\end{array}$ \\
\hline $\begin{array}{l}\text { Managers of Establishment Cannot Remotely } \\
\text { Access to Financial Data at Any Time }\end{array}$ & $\begin{array}{l}\text { Managers of Establishment Can Remotely Access } \\
\text { to Financial Data at Any Time }\end{array}$ \\
\hline $\begin{array}{l}\text { There is not a Constant Communication with } \\
\text { Customer Establishments for Financial } \\
\text { Consultants }\end{array}$ & $\begin{array}{l}\text { There is a Constant Web-Based Communication } \\
\text { with Customer Establishments for Financial } \\
\text { Consultants }\end{array}$ \\
\hline
\end{tabular}

\subsection{Risks}

It should be known that there are always risks and that hundred per cent safety is not available in the environments of information technology. Therefore, what needs to be done in a risky environment by nature is to understand what the risks may be and to reduce the possible effects of them to an acceptable level with the precautions to be taken (Y1ld1z, 2011).

While the establishments perform a risk assessment, it must be remembered that each risk is matched to an opportunity, and the assessment of the loss that may be encountered as a result of the risk along with the gains of the cloud computing opportunities must be done very well considering all the related components beginning from the special conditions, dynamics and activity area of each establishment (Korkmaz, 2010).

In cloud computing models, risk levels and the responsible parts are described separately. The biggest responsibility in maintaining the system security in Software as a Service (SaaS) model belongs to the service provider. In Platform as a Service (PaaS) 
model, the system security is shared between the service provider and customer establishment. The user is responsible for security in Infrastructure Services (IaaS).

The general risks of using cloud computing in accounting field have been examined under three titles as "Risks Arising from Service Providers", "Contractual Risks" and "Risks Arising from Legal Structure".

\subsubsection{Risks Arising from Service Providers}

a) Physical Infrastructure: Due to the deficiencies and weaknesses in the computer hardware, network topology and the physical facilities (building, power, backup, air conditioner, etc.) equipped by the cloud computing service provider, there is the possibility that the stored data may be possessed by the malicious third parties (Molnar and Schechter, 2011).

b) Software Infrastructure: The fact that the software infrastructure or operating systems built by the service provider are far from meeting the expectations of customers jeopardizes the system. This structure may cause the data to be possessed by the malicious third parties (Molnar and Schechter, 2011).

c) Human Resources: The human resource that will manage and lead the system must have the technical knowledge and skill to meet the expectations of the customers. Also, there must be a communication center that will actively provide service to the customers at all hours of the day and night. The personnel must be selected with direct methods, and the necessary measures must be taken in order to prevent the personnel from forwarding the customer data to the malicious third parties (Molnar and Schechter, 2011).

Another risk issue is that you cannot control your own data, that you even do not know where they are stored and that you cannot fulfill your legal obligations. The data that you transfer to the cloud environment have been given up to the expert staff of the service provider. In this case, it would be appropriate to certify that the service provider has the qualified experts, to follow their actual work and to find the necessary certificates if available, and to even insert provisions to the contracts or service level agreements (Y1ldiz, 2011).

d) Slow-Running Applications and Service Issues in Low Speed: Web-based cloud services have been designed to work with the broadband Internet. Therefore, upload and download speed of the Internet connection affect the use of cloud services. In the environments without broadband Internet, it may take long time to transfer the large-size data to the cloud (Henkoğlu and Külcü, 2013). This situation significantly affects the service quality.

e) Cloud Environments Become a Target for Attacks: While there is the risk to lose the data on cloud computing system due to the reasons such cyber-attack, it is also possible that the data stored on personal computers may get harmed. But just as the disappearing of the customer's money in the bank is an unacceptable situation, it is also unacceptable to lose the data, which are always considered as priceless for the user, from the cloud. As in all the services that use the Internet technology, cloud computing services have defenseless sides against traditional Internet attacks (audio surveillance, unauthorized access, data modification, etc.) as well. Considering the significant cyberattacks and large data losses that occurred in 2011, it is remarkable that the environments and systems such as cloud system where large data and personal 
information are stored are set as target (Henkoğlu and Külcü, 2013).

\subsubsection{Contractual Risks}

a) Risks Arising from Uncovered Costs: The security infrastructure of cloud computing built and run by the service providers has been configured to protect the customer whenever he/she is online. The cost of protecting the customer from the malicious third parties whenever he/she is offline may reach to an amount that the customer cannot cover (Molnar and Schechter, 2011).

b) Deceptive Pricing: The excess demand because of the low prices offered by the service providers due to the competition may increase the use amount of the system too much. As some systems cannot bear this overload due to the insufficiency of the infrastructure, they can be open to threats (Molnar and Schechter, 2011).

c) Excessive Transition Costs: The customers cannot quit the system sue to the high prices given by the service providers, and the customers feel as if they are trapped (Molnar and Schechter, 2011).

d) Bankruptcy: Service providers have the probability to leave the sector after going bankrupt. This situation may cause the customers to have difficulty in accessing to the stored information (Molnar and Schechter, 2011). Also, while the amendments on specifications that may happen in case of the purchase of a cloud computing service provider by another one can put the establishments in a difficult position, technical and financial difficulties that a service provider may experience can cause the establishments to incur great data and prestige losses (Korkmaz, 2010).

e) Addiction Service Provider: In case of a request to transfer from a cloud computing service provider to another one, huge difficulties are encountered in data and software transfer due to the reasons such as that the interfaces of software programming of cloud computing service providers are not duly standardized and that the data are stored in database schemes specific to the service providers. As a result, it is observed that the establishments are somehow dependent on the cloud computing service providers (Korkmaz, 2010).

f) Data Security: Another issue is that it cannot be clearly distinguished as the data are stored along with the data of the other establishments in a single place. Therefore, in case of any disaster (flood, earthquake, fire, etc.), it cannot be always possible to ensure the security of the data and to maintain the sustainability of the system (Y1ldiz, 2011).

In relation to this, the service provider must be able to maintain the sustainability of your access in case of any disaster. In this case, it must be examined if the emergency and business continuity applications are on site or the certificates regarding the independent audits must be requested. In the contracts or service level agreements to be issued, it is important to specify the reuse periods of the system and also to conduct related tests from time to time (Y1ldiz, 2011).

\subsubsection{Risks Arising from Legal Structure}

a) Indirect Legal Enforcement: In any illegal processes done by the customers, the digital data kept by the service provider can be confiscated in order to check all the data. Also, the customer establishment may be restrained from making a transaction for a certain time (Molnar and Schechter, 2011). 
b) Confidential Investigations and Researches: Service providers may have to share the customer data without notification in the confidential investigations conducted by the related governmental agencies (Molnar and Schechter, 2011).

c) Direct Judicial Enforcement: Service provider has the opportunity to reveal the tax-related or structural problems of the customer company by clandestinely viewing the customer data (Molnar and Schechter, 2011).

\section{The Precautions to be Taken Against the Risks of Cloud Computing in Accounting Field and The of The Solution Offers}

Despite all the potential benefits, there are some points that the establishments must pay attention due to that cloud computing technology is a developing model and that is has the above-mentioned risks. In this regard, it is very important to especially check thoroughly what kind of guarantee the service-providing establishment offers in terms of security and service quality, and to select the service-selling establishment accordingly. The establishments must receive detailed information from the service providers about the service that they will purchase, must evaluate to what extend these services will fulfill their requirements, and must have adequate information about what kind of risks this service has. Also, they must pay attention to that the agreement made with the service provider must be issued so as to minimize these risks. In this regard, the other point is that the standards related to these technologies have not been completely formed yet. This situation may require the establishments to wait a little more. Additionally, it must be guaranteed that the problems are properly handled in legal terms (Seyrek, 2011).

It is observed that the legal infrastructure in terms of maintaining the information security and protecting the personal data has not been formed yet in Turkey, and that the users are left alone in terms of taking responsibility and measures regarding the information security in cyber environment. Although Turkey signed many works and agreements made within the European Union (agreements no: 108 and 185, etc.), it cannot be put into practice as the necessary regulations cannot be made in the municipal law. Necessary legal regulations must be made as soon as possible in order that the security clauses (legal rights of consumers regarding the data transfer) covering the users of only specific countries (such as USA, Australia, AEA and Switzerland) that take part in these cloud service agreements must be in effect for also the users utilizing the cloud services (Henkoğlu and Külcü, 2013).

The primary measures that need to be taken in order to maintain that cloud system, which is the rising value of information and communication technologies utilization, can be safely used at maximum level by minimizing the existing risks in cloud computing field can be listed as follows (Henkoğlu and Külcü, 2013):

a) National information security policy must be developed and cloud computing issue must be specifically included.

b) Legal regulations regarding the personal data protection, in which the sensitive information are clearly explained, must be issued and put into effect.

c) It must be obligatory that the service providers, which will provide cloud computing service, must meet the necessary preconditions and international standards in order to operate in the service area and they must be ranked within a certification system. 
d) The most basic solution to protect the data security and personal information is to maintain secure communication and to encrypt the data. Therefore, legal regulations and audits must be done in order to allow the cloud computing service providers to take the basic security measures as a standard.

e) Cloud computing service providers must be audited within the scope of the specific information security criteria.

f) Training programs must be scheduled in order to raise awareness, so that the users can be informed about the content of the user service agreements and can select the cloud service providers from which they will get service.

g) Legal regulations must be done in order to obligate the use of secure communication protocols and top-level identity verification standards, so that the user data and privacy can be protected after any possible disasters that may occur.

h) International-level works (such as European Union agreements) must be participated and harmonization processes for developing cooperation must be accelerated, so that the cloud system users in Turkey can seek their rights or their rights can be protected within the scope of international conflict, cyber-crimes and personal data protection.

The general risks that have arisen with the use of cloud computing and the solution offers are effective for all the sectors that use cloud computing and for the accounting sector as well. Service providers that operate in accounting sector are responsible for keeping and preserving the digital financial data that are vitally important for the companies. Service providers need to take all the necessary technical measures, so that the digital data are not damaged, lost and possessed by the malicious third parties.

For this purpose, the recommended model for the establishments that provide cloud computing-based accounting service is described in Figure 4.

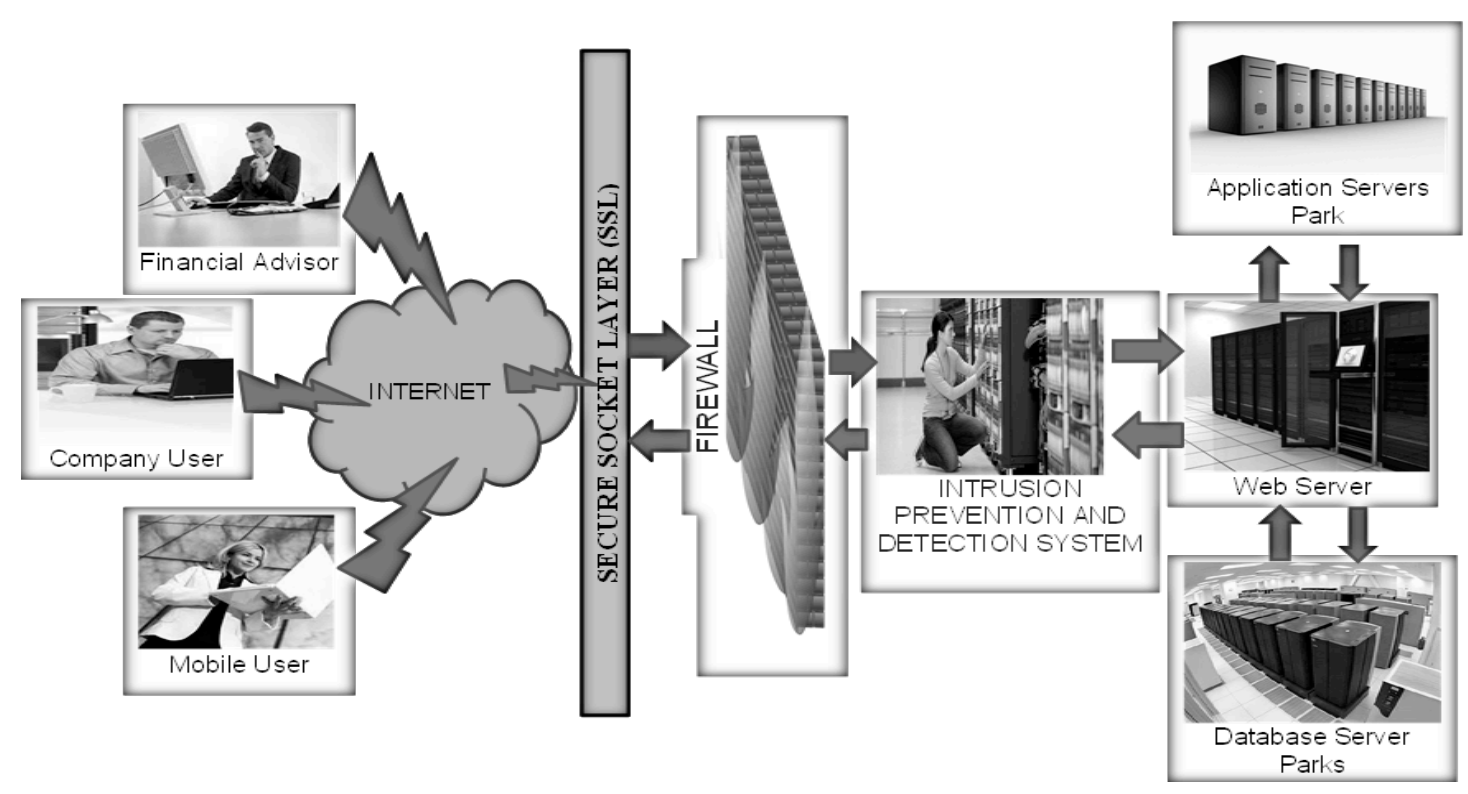

Figure 4. Recommended Working Model of Cloud Computing-Based Accounting Systems 
There are three types of user as "Financial Advisor", "Company User" and "Mobile User" in the system running in the web-based Internet environment. Every user can connect and make a transaction at any time and place through a fixed or mobile device with Internet connection to the system. Within the scope of these "Secure Socket Layer (SSL)" security protocols in this model, the applications such as access restriction, identity verification and one time password must be arranged by the service provider and the system security standard to be maintained must be adequate.

All information that are entered in the system through the secure communication media by the user reach the cloud service area. The information that reach this area are filtered via "Firewall" and "Intrusion Prevention and Detection System" created by the service provider, the threats are detected if available, and then a series of security tests such as authentication are performed. After that stage, the secure "Private Cloud" area of the service provider is accessed. On this area, there are "Web Server", "Application Server Park" and "Database Server Park" where the data are stored. On this area, service provider must build the sufficient technical infrastructure that will meet the requirements of the users in a short time and where the data will be securely stored. Service provider must continuously supply the qualified manpower in order to run this system to be built.

\section{Conclusion}

Cloud computing, as a popular structure today, created lots of new job contexts. This structure is not just a technological improvement, but also a system that fulfills the need for real-time remote business follow-up and that provides cost and energy saving meanwhile. The terms "cost and energy" are the keywords for a sustainable development and a well-functioning economy (Kuyucu, 2011). But the fact that the standards related to cloud computing technology have not been formed thoroughly yet returns to haunt us. This situation causes the establishments to encounter various risks when using the cloud computing technology. Besides, it is seen that there are many loopholes regarding the matter.

Cloud computing is a huge wave that will take hold of all the sectors and establishments. There is no doubt that one of the areas that this wave will create the biggest movement in the following years will be law. Hence, in the presence of such uncontrollable change of technology, the laws need to be harmonized with the required standards at the same speed.

There is a need for well-planned country policies in order that the cloud computing technology can grow and can be applied properly in private sector. The needs of the sector must be livingly confirmed with the organizations to be arranged and the necessary measures must be immediately taken. The authority must shift to the active status from passive status. So, the state authority will have minimized the cloud computing risks through the existing means. As a result, cloud computing technology will be economically benefited at maximum level.

Turkey is a significant actor in information sector with its growing economy that opens to foreign countries. Today, many information companies design various applications and put them on market by using the cloud computing infrastructure. However, there is not any government incentive policy that will encourage and support the investments on cloud computing field. The "European Union Cloud Computing Policy Report" that has been issued recently will be able to build the infrastructure that 
will increase the incentives on this area. Also, it is expected that Turkey, which is in the full membership process, will be affected from this development in European Union (Kuyucu, 2011).

Legal regulations must be made in order to protect the data security and privacy of the users utilizing the cloud computing services in Turkey on cloud. Cloud computing exists within a vast area of legal liability. The context of "Personal Data Protection", which is tried to be protected under a federal law in USA and which was framed with the Agreement no: 108 and the additional Protocol no: 181, is still being discussed in the agenda of the parliament as a law draft in Turkey. The Privacy Act Draft must be enacted as soon as possible in order to effectively protect the digital data of the users utilizing the cloud computing service and also to reinforce the trust on the cloud computing service providers (Henkoğlu and Külcü, 2013).

The primary sector where cloud computing began to be used is the rapidlyemerging service sector. Cloud computing offers important opportunities for the establishments that try to gain a consistent price advantage in service sector. For the establishments that provide accounting software service, developing web-based applications that will utilize the cloud computing facilities will provide significant advantages in the competition. In today's competitive environment, it is the primary goal of the establishments to build and manage the accounting systems for a low cost and with advanced technological facilities within a secure structure that can be constantly and remotely followed. Accounting systems that benefit from the web-based cloud computing opportunities have the structure to fulfill these requirements. The fact that cloud computing is a very new concept in accounting sector, and that its legal infrastructure has not been thoroughly built yet in Turkey and its natural risks raise a question mark in the minds of the establishments in terms of the operation of the system.

The general risks that have arisen with the use of cloud computing and the solution offers are effective for all the sectors that use cloud computing and for the accounting sector as well. Service providers that operate in accounting sector are responsible for keeping and preserving the digital financial data that are vitally important for the companies. Service providers need to take all the necessary technical measures, so that the digital data are not damaged, lost and possessed by the malicious third parties.

The establishments that provide accounting systems services utilizing the cloud computing facilities in accounting sector must build the necessary infrastructure and models by foreseeing the general risks of cloud computing technology and the structure in the country in order to run the system without failure and to store the digital financial data of the establishments in a secure environment. 


\section{References}

Armutlu, H. \& Akçay, M. (2013). "Bulut Bilişimin Bireysel Kullanımı İçin Örnek Bir Uygulama”, Akademik Bilişim Konferans1 - 2013, 23-25 Ocak.

Atay, İbrahim (2010). “Cloud Computing Düşüncesi”, available. Retrieved on October 20, 2013, from http://www.yazilimdevi.com/Makaleler-1010-cloud-computingdusuncesi.aspx.

Bojanova, I. \& Samba, A. (2011). "Analysis of Cloud Computing Delivery Architecture Models", Workshops of International Conference on Advanced Information Networking and Applications, 453-458.

Henkoğlu, T., \& Külcü, Ö. (2013). "Bilgi Erişim Platformu Olarak Bulut Bilişim: Riskler ve Hukuksal Koşullar Üzerine Bir İnceleme”, Bilgi Dünyası, 14(1), 62-86.

Hu, P. and Hu, F. (2010). "An Optimized Strategy for Cloud Computing Architecture", Computer Science and Information Technology (ICCSIT), 2010 3rd IEEE International Conference on, 9, 374-378.

Korkmaz, Y. (2010). "Bulut Bilişim Risk Değerlendirmesi - I", Retrieved on October 15, 2013, from http://www.bilgiguvenligi.gov.tr/guvenlik-teknolojileri/bulutbilisim-risk-degerlendirmesi-i-2.html.

Koyuncu, M. (2011). "Bilişimde Yeni Trend: Bulut Bilişim", Retrieved on October 20, 2013, from acikarsiv.atilim.edu.tr/browse/503/17.pdf.

Kuyucu, H. A. D. (2011). "The playground of cloud computing in Turkey", Procedia Computer Science, 3, 459-463.

LUCA Projesi Hakkında, Retrieved on October 20, 2013, from www.luca.com.tr.

Maqueira-Marin, J. M., Brugue-Camara, S. \& Moyano, J. (2009). "What does grid information technology really mean? Definitions, taxonomy and implications in the organisational field", Technology Analysis and Strategic Management, 21(4), 491-513.

Molnar, D. \& Schechter, S. (2011). "Self Hosting vs. Cloud Hosting: Accounting for the security impact of hosting in the cloud", Retrieved on October 5, 2013, from http://weis2010.econinfosec.org/papers/session5/weis2010_schechter.pdf.

Selvi, O. (2011). Bulut Bilişim ve Eğitim Alanında Örnek Bir Uygulama. Yayınlanmamış Yüksek Lisans Tezi, Süleyman Demirel Üniversitesi Fen Bilimler Enstitüsü, Isparta, Turkey.

Seyrek, İ. H. (2011). "Bulut Bilişim: İşletmeler İçin Firsatlar ve Zorluklar”, Gaziantep Üniversitesi Sosyal Bilimler Dergisi, 2, 701-713

Sultan, N. A. (2010). "Reaching for the "cloud": How SMEs can manage", International Journal of Information Management. 31, 272-278.

Yapıc1, C. (2010). Bulut Bilişim Dosyası. Retrieved on October 20, 2013, from www.tubisad.org.tr/Tr/Library/Analizler/bulut_bilisim_dosyasi.pdf.

Yıldız, Ö. R. (2011). “Bilişim Dünyasının Yeni Modeli: Cloud Computing”, Sayıştay Dergisi, 74, 5-23. 